\title{
Optical Power Budgeting in Colorless WDM PON
}

\author{
Amir Razaq \\ Telecommunication Engineering \\ Institute of Communication Technologies \\ Islamabad, Pakistan
}

\author{
Shahzada Alamgir Khan, PhD \\ Associate Professor \\ Telecommunication Engineering \\ Institute of Communication Technologies \\ Islamabad, Pakistan
}

\begin{abstract}
In the recent years, Passive Optical Network (PON) has gained engrossed attention of research engineers and network service providers due to tremendous economic benefits and optical detection. In this research work, RSOA and AWG wave guided array based bi-directional PON system is demonstrated. The combination of two devices is designed for obtaining high data rates and wide bandwidth in WDM-PON. In this research work, three types of PON are designed the first passive optical network system is designed on channel RSOA without using AWG in the channel, the second system using RSOA with AWG and finally the system using bidirectional reflective filters with AWG. The simulation results and comparison of proposed three PONs shows the new system uses array waveguide grating to increase the capacity and make multiplexing to the entering signal then routing it to the users. The proposed work is having large lock-in range, and its usage will demonstrate its recital in future network planning.
\end{abstract}

\section{Keywords}

WDM PON Network, RSOA, bit error rate (BER), AWG and Network Quality.

\section{INTRODUCTION}

\subsection{Development of PON}

This document deals with the functional design of the PON system that is integrated through several types of configuration to design a new configuration of PON for to design two-way communication system that is based on reflective semiconductor optical amplifier (RSOA) and a filter. The role of optical networks is to connect the central office (CO) as service providers to end users, whether commercial or residential. It was in 1988, and end users with access to the network using an optical fiber to a point Multipoint called P2MP networks.

\subsection{TDM-PON Vs WDM-PON}

The TDM-PON serves few users and that too with low data rates as optical power is split through 1 to $\mathrm{N}$ power splitter. Contrarily, WDM-PON has the capacity deliver higher amount of data to as many users as required. The basis of TDM-PON is synchronized slots in fixed quantity thus making it difficult to scale. On the other hand, only possible limitation in WDM-PON is availability of wavelength quantity. There are many other key differences as well.

\subsection{WDM}

The optical communities have enormous bandwidth capacity that can be as high as a thousand instances the complete RF spectrum. WDM is a vital technology that is used in telecommunications systems. The WDM networks permits the wavelength routing in dissimilar fiber acquaintance for the similar wavelength that can be used repeatedly.

\subsection{Benefits and trials of WDM-PON}

The passive ODN among OLT and ONU permits a higher irresponsibleness' of a WDM-PON system. These are the following benefits are offered by the WDM-PON. Much attention to the satisfactory interference in WDM-PON (i.e., Inspired by $3-5 \mathrm{db}$ ) to increase transmission distance and boost the ability budget capacity and increase remote transmission from TDM-PON, own dimensional channel, work at the highest rate of its dimension, Creates a correlation between each WDM-PON, OLT and ONU.WDMs are temperature sensitive because the channel dimension is to be converted according to the temperature of the changed temperature. The operating temperature settings are controlled by the ingredients that may require. Instead, the WDM is aware of the problem of many different types of challenges.

\subsection{Thesis Goals \& Hypothesis}

How broadband services are served in a colorful WDM-PON is explained in this document. The most important issue is to accidentally adjust the cost of manufacturing WDM-PON. To transfer the data from ONU to OLT, some signals are received to be restored with some optimization when receiving at the ONU socket. Such program is beneficial for reducing the cost of WDM-PON laser devices while facilitating the management of its network. A fiber optic connection to the optical energy cost of the optical energy that is used by device (from the given supply that started on a given fiber) available, many driven mechanism, such as loss of the bridge, signal of sufficient power.

\subsection{Research Approach \& Impact}

The majority of research for designing of networks and their field implementation was simulated using Optic wave Optic System. The majority of research for designing of networks and their field implementation is simulated using Optic wave Optic System. The research also takes into account components such as AWG, MUX, DEMUX, and DPSK.

\subsection{Latitude/Scope of Project}

The ideas of this work may apply to multiple networks. Combining an integrated PON system with RSOA reduces installation. Passive optical networks can be networks that are used to transporting CO optical signals to buyers. WDM-PON with AWG provides some compensation for truncated prices, high wavelengths, low packet loss, reduced size, and repeated wavelength routing for systems that provide system locationdemanding equivalent wavelengths for victimized RSOAs. This module is named (a colorless) and RSOA is cheaper than optical equipment. 


\section{ARRAY WAVEGUIDE GRATING (AWG)}

\section{A. Rudiments of array waveguide grating}

The basic concept of this section is to underlie the way on which this thesis is going to present. Primarily discourse the concepts of PON, RSOA, AWG and multiplexing are going to discuss. For each one concept, a quick and complete review will be carried out. This includes the main concepts, the advantages and types available that distinguish its use in practice. An extraordinary expedient that has been fabricated by expending various flat wave machineries and has founded a variety of submissions in light waves systems. WDM is the waveguide sample or AWG. Group waveguide wave (AWG) is based on diffraction concepts. An AWG expedient is often entitled an optical waveguide, a waveguide network, and a routing or phasor layout router. An AWG instrument includes a series of curved channel waveguides with a constant transformation within the period of the optical path between adjacent channels. A waveguide model (AWG) is an over simplification of the Mach-Zander interferometer.

Arrayed Waveguide Gratings (AWGs) are commonly used as optical demultiplexers in multi-dimensional wavelength structures (WDM). These gadgets are capable of multiplying the range of wavelengths in a single fiber, significantly increasing the transmission capacity of the optical network.

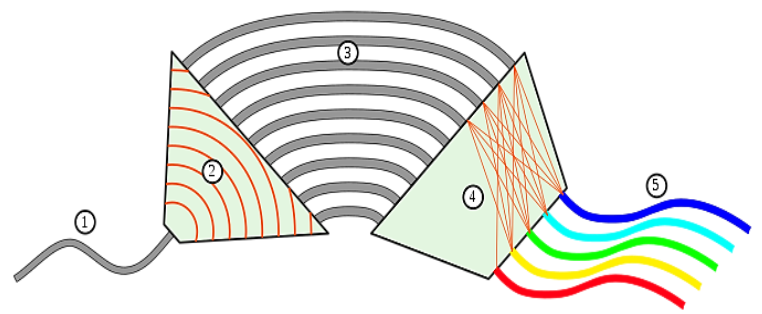

Figure 1

The AWGS consists of a number of output couplers (1) (5), an area of propagation of the unfastened area (2) and (4) and the grid waveguides (three). The mesh includes a huge range of waveguides with a set duration $(\delta 1)$ boom. The mild is attached to the device thru an optical fiber (1) related to the inlet port. The light diffraction from the input waveguide driver to the interface/coupling plate is propagated through the free space place (2) and illuminates the grid by using Gaussian distribution. Each wavelength of mild coupled to the grid waveguides (3) undergoes a steady segment shift attributed to growing the constant period of the grid waveguides. The light diffused with the aid of every network waveguide interferes constructively and is concentrated on the output waveguides (5), in the spatial role, at the output channels, depending at the wavelength of the matrix segment.

Let us understand the maneuver of AWG as ophthalmic demultiplexer:

- Step-1: As shown inward bound mild signal partaking all wavelengths $(\lambda-1, \lambda-2 \ldots \lambda-n)$ are fed the use of optical fiber (F) into enter fissure or enter coupler (precise as 'S1') part of the optical AWG (Arrayed Waveguide Grating).

- Step-2: This multiplexed signal is surpassed via loose area part of 'S1'.

- Step-3: next, mild receives alienated into array of waveguides. Here segment postpone proportional to wavelength is delivered to optical alerts exceeded from oneof-a-kind waveguides of various lengths.
- Step-4: Now those section delayed alerts are completed to skip from output fissure or output coupler (targeted as 'S2'). This hollow space is hooked up to multiple optical fiber cables. At this level, light signals after transitory thru unique lengths of waveguides will intrude with one alternative. As a result, each output optical fibers are fed with one precise wavelength of mild having the most bountifulness.

- Step-5: At this stage, with using a couple of optical fiber cables exceptional wavelengths of light are taken because the output.

The following are the characteristics of the optical network:

- As revealed directly above, it is used as an optical multiplexer. This solicitation is used in the DWDM network for multiple WDM multiplexing in a fiber optic cable.

- It is used as ophthalmic decoders at the end of the DWDM network receiver.

- AWGs are used in the OADM that is part of the long distance fiber communication system.

- Used in FTTx optical systems, for example CWDM MUX and DEMUX.

A major WG property is the permitted phantom range (FSR), likewise recognized as the multiplexer periodicity. Periodicity stems from the fact that the productive boundary in the field of free output propagation can ensue for many dissimilar wavelengths. The FSR indicates the wavelength or frequency spacing between the maximum of the crossing point model and can be acquired as surveys [41]:

$F S R=\frac{\lambda_{0} n_{c}}{m n_{g}}$

Equation No. 2.1

Where $\mathrm{m}$ is a numeral, $\lambda_{0}$ is the essential wavelength, $\mathrm{n}_{\mathrm{g}}$ is the clutch refractive catalogue of the waveguides and $n_{c}$ is the real index in the waveguides arranged.

The maximum number of $\mathrm{N}_{\max }$ wavelength I / O channels be contingent on the FSR. The multiplex light bandwidth (channel spacing product and the maximum number of wavelength channels) $\mathrm{N}_{\max } * \Delta \lambda$ must be narrower than FSR to avoid overlapping orders. Therefore, $\mathrm{N}_{\max }$ can be derived as,

$N_{\max }=\int\left(\frac{F S R}{\Delta \lambda}\right)$

Equation No. 2.2.

Whereas $\Delta \lambda$ is channel spacing in the system.

An optical circulator is an excellent fiber optic segment that might be used to isolate optical signals going inversely into an optical fiber, such as the activity of a microelectronic circulator. Optical circulators have single-phase non-selective devices and three doors, ideal for bi-directional light on a single fiber. We offer unidirectional (PM) and polarization support (PM adjustments). These optical circulators are ideal for compatible frame applications and fiber sensor applications. Our one-dimensional circulators also incorporate a broadband circulator for the OCT. An optical circulator is a three or four-way arrangement delineated so that the light entering any entry leaves the escort. This means that if the light enters input 1 , it is discharged from port 2 , however, if the part irradiated light is reflected in the pump, it does not leave the port 1 and the door 3 .

In a three-door circulator, sign a is transmitted from port 1 , port 2 , another sign is transmitted from door 2 , door 3 , and the quit can transmit a 3 rd sign from port three to port 1 . This 
conduct is represented through the subsequent. The call comes from the fact that a signal is transmitted from port 1 to port 2 , any other sign may be transmitted from port 2 port three, and sooner or later, a sign can be transmitted from port 3 to port 1 . In practice, one or doors used as entrances and the $1 / 3$ port is used as an exit.

There are easy examples of optical circulators. The primary is an EDFA utility amplifier (fiber amplifier doped with erbium) to enlarge a sign. The configuration for this motive with a three-port optical pump is shown within determine below.

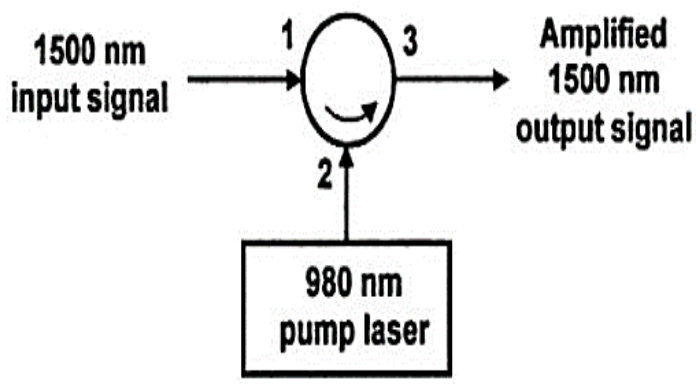

Figure 2

Port 2

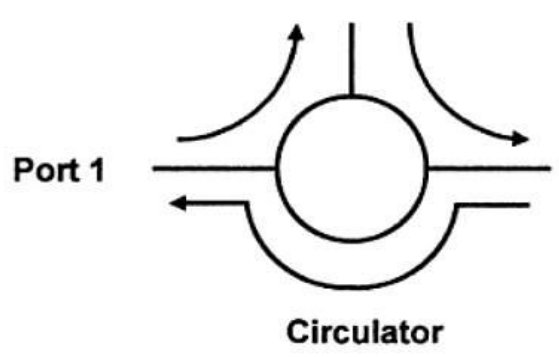

Port 3

Figure 3

The growing interest in administrations with quick access to progress in optical aggregation systems (PON) [31], after the measurement of the terminal gear between the center and the system reaches the layers is limited [43]. The RSOA is particularly suitable for future PON statements that give a strong amplifier that can conquer the requirement of flexible laser sources in the customer's home. The RSOA can be from a single source wave without UN imperfections (optical system unit) is shared between different clients and can even be opened and pinched this seed to help a WDM overlap mode that is independent of the length of WDM, wave.

The RSOA can be used as reinforcement. This provides a further advantage that allows you to avoid using a diffuser to plug erbium fiber (EDFA) into the frame. Contrary to what is known in any case, because of its possessions, it allows a greater gain from the SOA and the non-linearity gain is also fascinating for the variation of the wavelength. Optical intelligent speaker Semiconductors offers exceptionally advanced performance for WDM PON applications. This is mounted on the $20 \mathrm{~dB}$ cart, can be the optical semiconductor amplifier (SOA) positions at a cost of up to $1.5 \mathrm{~GB} / \mathrm{s}$ to provide visual information advantages for photo lasting (FTTH / FTTP) endless source custom wave length.

The RSOA is wise, since it plays different modulator elements not only (there is no obligation for a short laser source), but also a speaker. Think of the recognition of the contrasts in the tension provided to the SOA anode from a single organized piece. The current injectable estimate in RSOA considered flag information allowing the design of optical or SOA signals.

$\psi_{\phi}=\eta_{j} \frac{K_{B} T}{c} \ln \left[\frac{N_{\text {bias }}(Z)+N(Z)}{N_{\text {bias }}(Z)}\right]$

Equation No. 3.3

Where,

$\psi_{\phi=\text { Voltage variation }}$

$\eta_{j}=$ Reflective coefficient

$K_{B}=$ Boltzman constant

$T=$ RSOA temperatue

$c=$ Speed of lig $\square t$

$N_{\text {bias }}(Z)=$ Bias current level

$N(Z)=$ Current level

WDM is assessed for top capability communication systems. Every line is appointed to the various frequencies and multiplexed on-to one fiber. At the terminus point wavelengths are spatially detached to totally dissimilar earpiece localities. During this pattern the in height transferor information measure is employed to a bigger magnitude to communicate multiple optical signals through one fiber. WDM technique is shown in figure 3.6.

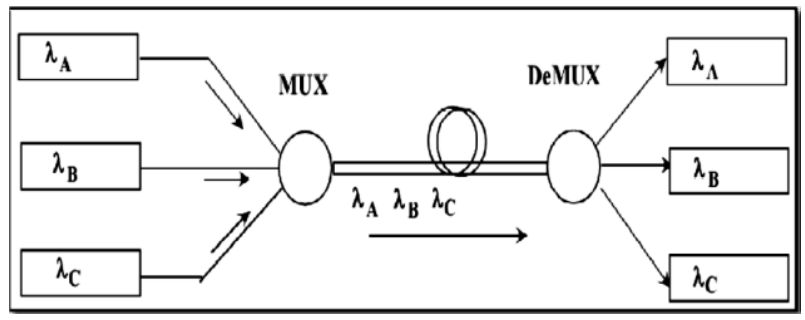

Figure 4: Implementation techniques of WDM

WDM Systems is shown in figure 3.7 and it is called pointpoint communication. For single point connections, the data rate is limited to $\sim 100 \mathrm{~GB} / \mathrm{s}$ due to scatter. This is far below the capacity of the optical carrier frequency. WDM can increase the total bit rate of point-to-point systems. For $\mathrm{N}$ bit rate channels B1, B2 ... BN conveyed simultaneously to an $\mathrm{L}$ length fiber, the product of the length bit is produced,

$$
B-L=(B 1+B 2+B 3+\cdots+B n) \cdot N
$$

To use the interval of be able to take advantage of the night to see the evil and directional, and the power of a variety of NS in combination with a divider so that the feeble AWG pass band in Figure 3.9. The most important pieces to each other, and composed to give NS modulator or void, by the armor of a standard is required in order to enhance and to improve the hold of the light to the preceding case. A variable optical Attenuators (Voase) to be able to achieve the same / track support without profit. Also, the form of parcels, NS allow hot swap [46]. Then back to the murder of at least p. So it can be a specific way to the knowledge of the harbor, the more one yields to the gadget: Here Similarly, it can be an advantage in a stage of motion AWG waveguide modulators various locations shown by the scenes display Programmable directly related to setting profile waveguide portion. Forming second region which then become free movement portion AWG back. This, however, may be used by the drive for the gadget and then, the interval of wavelength, the further advantage from the exchange for all their grants [44]. 


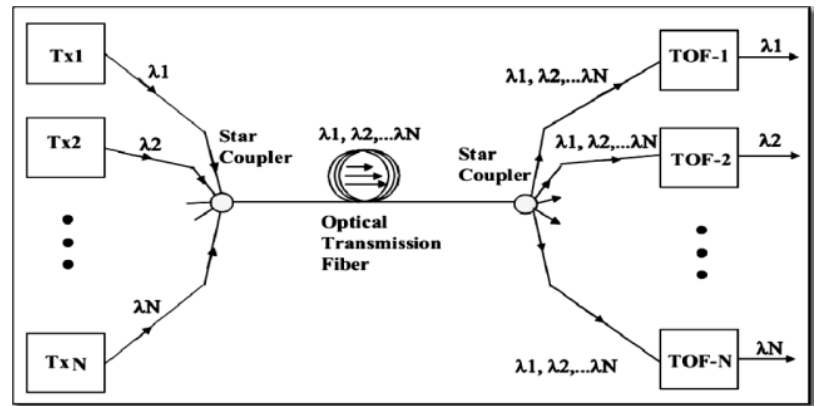

Figure 5

\section{B .System's Architecture Exploration And Simulation Setup}

This section reveals the structural design details of bidirectional passive optical network and also deliberates the implementation of the proposed system. Firstly model of the proposed system is described then explain the implementation environment details are presented and finally results are simulated are summarized. The main measurements and efficiency of each modulation is also explain in this chapter.

1) NRZ

Produces a Non Reappearance to Zero (NRZ) coded signal. NRZ Pulse Originator has amplitude 1volt and bit sequence equals 512 bits.

\section{2) PRBS}

It produces a Pseudo Random Binary Sequence (PRBS) as per diverse task modes. The bit succession is intended to estimate the attributes of arbitrary information.

3) Lithium Niobate Mach-Zehnder Modulator (LiNb-MZM) The Mach-Zehnder structure comprises of an information optical branch, which parts the approaching light into two arms, trailed by two free optical artilleries, which are in this way recombined by the yield optical branch. Utilization of an electrical flag to one of the optical arms controls the level of

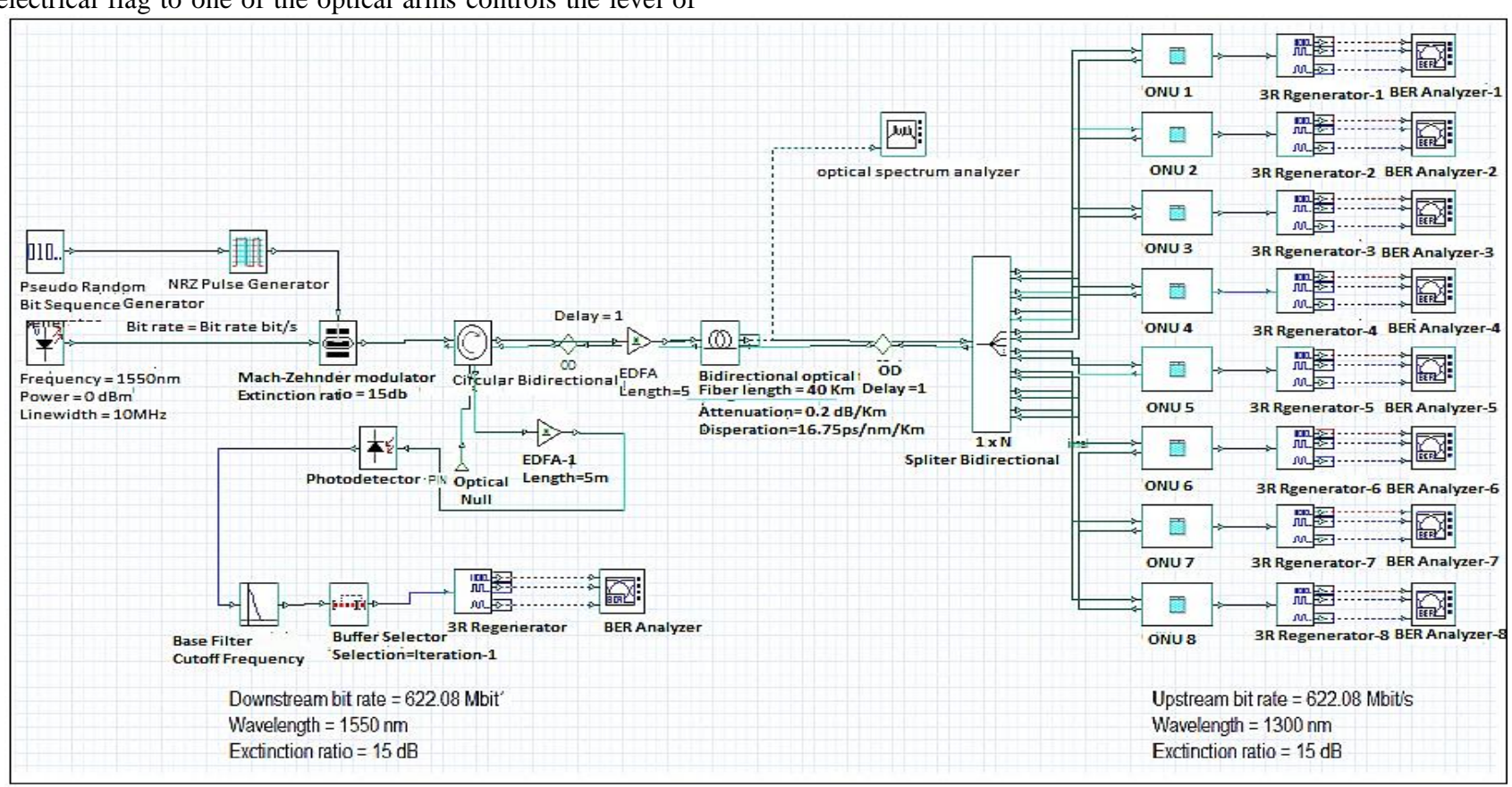

Figure 6: Bidirectional downstream and upstream Simulated Structure of PON for 32 users impedance at the yield optical branch and subsequently controls the yield force.

4) PD

An optical detector is a tool that converts light alerts into electrical alerts, which can then be amplified and processed. The photograph detector is as essential an element of any fiber optic gadget because the optical fiber or the mild supply. Photo detectors can dictate the overall performance of a fiber optic verbal exchange link. They offer true performance, being small in length, and are of low price. Photodiodes are made of silicon, germanium, etc.

5) AWG

Arrayed Waveguide Grating (AWG) is an optical maneuver centered totally on interferential singularities, and it has a intermittent performance in the wavelength area. The input optical signals in every port are routed to a selected output anchorage conditional on the sign wavelength and the enter seaport quantity.

6) RSOA

It simulates a reflective semiconductor optical amplifier including the dynamic dependence between electric and optical input signals.

7) Bidirectional SMF

The aspect simulates the bidirectional proliferation of indiscriminate conformation of optical signals in an unmarried-mode fiber. Raman interplay for an capricious formation of appraised and parameterized alerts is likewise taken into consideration. The element presents most of the functionality of the total area method fiber version.

The following considerations are used for the reproduction of the system.

The simulated structure of PON for 32 users is given below 


\begin{tabular}{|c|c|c|c|c|}
\hline Side & Component & Traffic Direction & Parameter & Value \\
\hline \multirow{10}{*}{ Transmitter } & \multirow{3}{*}{$\begin{array}{l}\text { NRZ and RZ Pulse } \\
\text { Generators }\end{array}$} & \multirow{3}{*}{ Both } & Amplitude & 1 a.u. \\
\hline & & & Rise Time & 0.05 bit \\
\hline & & & Fall Time & 0.05 bit \\
\hline & \multirow{6}{*}{ CW Laser } & \multirow{3}{*}{ Downstream } & Frequency & $1550 \mathrm{~nm}$ \\
\hline & & & Power & $0 \mathrm{dBm}$ \\
\hline & & & Line width & $10 \mathrm{MHz}$ \\
\hline & & \multirow{3}{*}{ Upstream } & Frequency & $1300 \mathrm{~nm}$ \\
\hline & & & Power & $0 \mathrm{dBm}$ \\
\hline & & & Line width & $10 \mathrm{MHz}$ \\
\hline & Match-Zehnder & Both & Extinction Ratio & $15 \mathrm{~dB}$ \\
\hline \multirow{4}{*}{ Channel } & \multirow{3}{*}{ Single Optical Fiber } & \multirow{3}{*}{ Both } & Length & $\begin{array}{c}20,40,60,80,100,120,140 \& \\
150 \mathrm{~km}\end{array}$ \\
\hline & & & Attenuation & $0.25 \mathrm{~dB} / \mathrm{km}$ \\
\hline & & & Dispersion & $16.75 \mathrm{ps} / \mathrm{nm} / \mathrm{km}$ \\
\hline & Optical Splitter & Both & Number of Users & $8,16 \& 32$ \\
\hline \multirow{3}{*}{ Receiver } & PIN Photo detector & \multirow{3}{*}{ Both } & Responsivity & $1 \mathrm{~A} / \mathrm{W}$ \\
\hline & \multirow{2}{*}{ Bessel Filter } & & Dark Current & $10 \mathrm{nA}$ \\
\hline & & & Cutoff Frequency & $0.75^{*} \mathrm{Bit}$ rate $\mathrm{Hz}$ \\
\hline
\end{tabular}

\section{Transmitter Phase/Stage}

This system contains PRBS generator for generating of random bit stream having the bit rate equal to the $10 \mathrm{Gpbs}$. This system initiated from the downstream transmitter, and then enters into the NRZ pulse generator. The NRZ pulse generator transfigures the stream pulse into the waveform pulse as revealed in the figure 4.4. Table 4.2 elaborates the performance parameters of the $\mathrm{CW}$ laser. Frequency indicator designates the fundamental incidence of the $\mathrm{CW}$ laser. The central frequency of the laser is use to determine the wavelength of the emitted wave. The output power of the light wave is specified by the average power, while the width of the frequency intermission of the total secretion area is characterized by the line width. Preliminary segment of oscillation provides the initial pulse to generator to produce the wave light. The LiNb-MZM is used to modulate the pulse signal. It can the observed from the figure 4.3 of the central office, the wavelength of the carrier signal for the $\mathrm{CW}$ laser is 1552 and power is $1 \mathrm{~mW}$.

Table 2:Parameters for the CW-laser

\begin{tabular}{|c|c|}
\hline CW laser parameters & Values of parameters \\
\hline Frequency & $1552 \mathrm{~nm}$ \\
\hline Power & $0 \mathrm{dBm}$ \\
\hline Line width & $10 \mathrm{MHz}$ \\
\hline Initial phase & 0 degree \\
\hline
\end{tabular}

\section{Bi-directional Channel Stage}

A bidirectional fiber of $50 \mathrm{~km}$ is used to accelerative the signal and backwards. With an optical deferral of 1 unit to dispersed the ascending and descending flow. Table 4.3 shows the main restrictions of a bidirectional optical fiber. The fiber cable has a loss of attenuation of $0.22 \mathrm{~dB} / \mathrm{km}$ and a length of $50 \mathrm{~km}$, this entails there is a $0.22 \mathrm{~dB} / \mathrm{km} * 50 \mathrm{~km}$ which equates to a power loss of $11 \mathrm{~dB}$. The channel consists of two circulators, bidirectional optical fiber and power divider.

Table 3: Parameters for the C-W laser with Desperation slope of $0.075 \mathrm{ps} / \mathrm{nm}^{2} / \mathrm{km}$

\begin{tabular}{|c|c|}
\hline Parameters & Values \\
\hline Length & $50 \mathrm{Km}$ \\
\hline Reference Wavelength & $1552 \mathrm{~nm}$ \\
\hline Attenuation & $0.22 \mathrm{~dB} / \mathrm{Km}$ \\
\hline Dispersion Slope & $0.075 \mathrm{ps} / \mathrm{nm}^{2} / \mathrm{Km}$ \\
\hline Dispersion & $16.75 \mathrm{ps} / \mathrm{nm} / \mathrm{km}$ \\
\hline
\end{tabular}

\section{Bi-Directional PON System with RSOA And AWG (Upstream and Downstream at RN):}

This topic reveals the structural design details of bidirectional passive optical network and also deliberates the implementation of the proposed system. Firstly model of the proposed system is described then explain the implementation environment details are presented and finally results are simulated are summarized. The main measurements and efficiency of each modulation is also explain in this topic. 


\section{Transmitter Channel Stage}

The transmitter stage of the proposed system is same as the previous discussed chapter. As it is concluded from the results of the previous chapter that the upstream received power is equal to the $-6.45 \mathrm{dBm}$ and the minimum bit error rate is equal to the $4.5 \times 10^{-19}$.

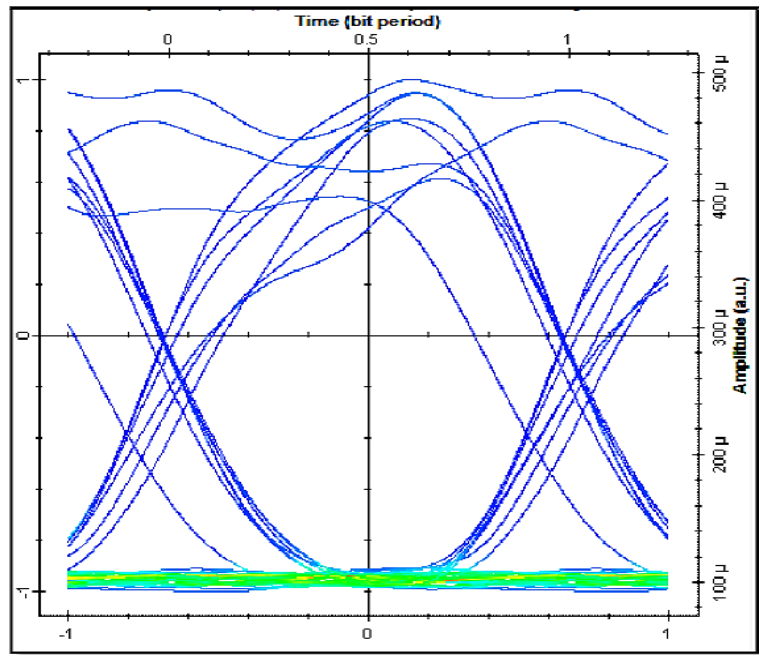

Figure 7

\section{Bi-Directional Channel Stage}

The bidirectional stage of the channel is consisted on the circulator, bidirectional optical fiber length of $20 \mathrm{Km}$ to 150 $\mathrm{Km}$ and AWG as illustrated in the figure 5.2. The influence of the input signal for the conduit is equal to the $-1 \mathrm{dBm}$ and its spectrum is shown in the figure 5.3. The main parameters of the AWG components are presented in the table 5.1. The power for the output signal for the AWG is equal to the $6.7 \mathrm{dBm}$ and its variety is shown in the figure 8 .

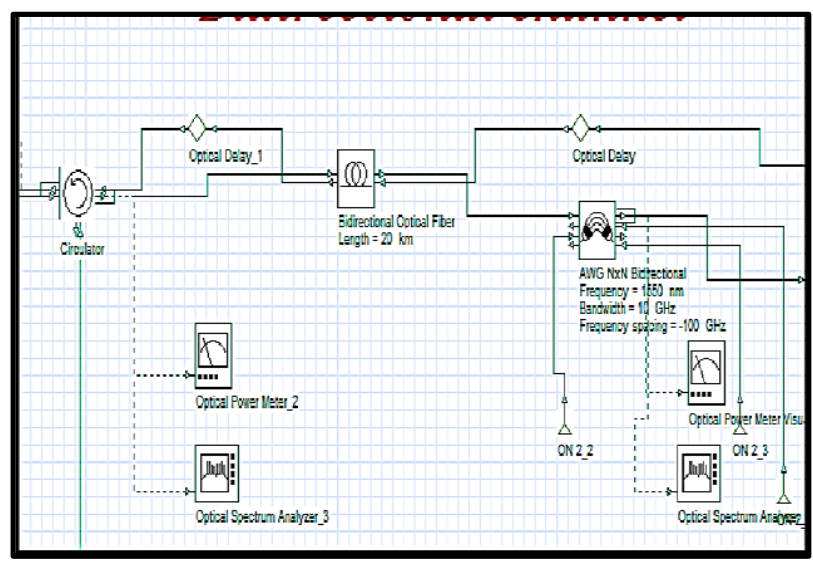

Figure 8

\section{Receiver Stage}

The simulated diagram for the receiver stage is same as given in the previous chapter therefore the value of the downstream power is $-9.7 \mathrm{dBm}$ and the minimum bit error value is $7 \times 10^{-26}$. Figure 5.5 and 5.6 demonstrated the received signals after PD.

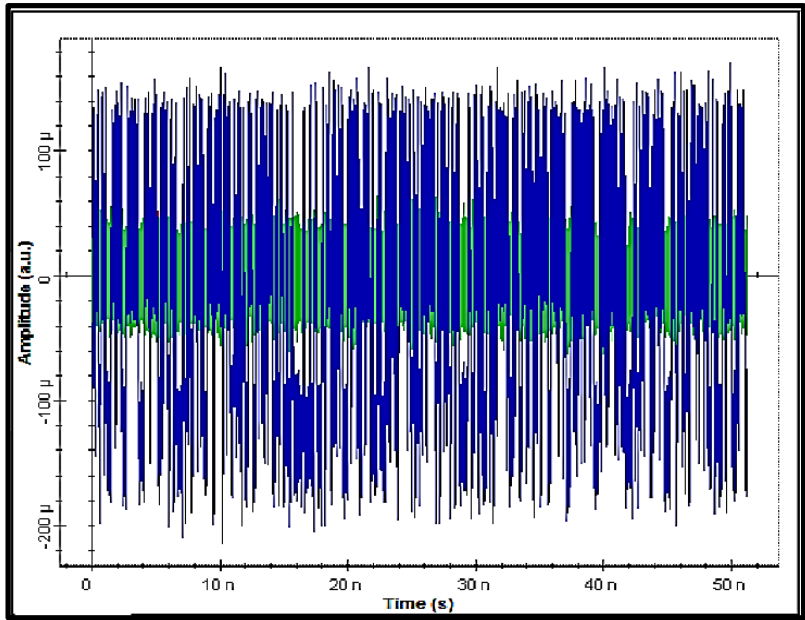

Figure 9:Properties of received signals at PD -9.7dBm

\section{Bi-Directional PON System with AWG at RN and bidirectional RF at user}

At $\mathrm{PN}$ a fiber brag grating filter is used as reflective filter. The RFB is reflects backs the input signal to the control office also receive the signals from the photo detector. Due to low in cost this device is used as transmitter at the RN side. Whereas the RSOA does not have filter but it have the ability to amplify the input signal and transmitted back to control office.

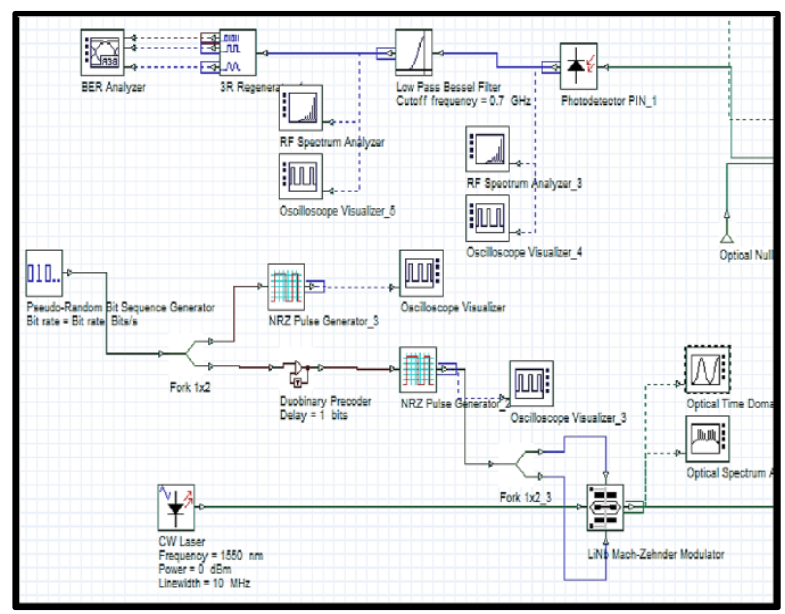

Figure 10: Simulated architecture of the PON integrated with AWG

Table 4: Comparison between PON systems based on RFB and RSOA

\begin{tabular}{|c|c|c|}
\hline Type of PON & $\begin{array}{c}\text { PON based on } \\
\text { RSOA }\end{array}$ & $\begin{array}{c}\text { PON based on } \\
\text { RFB }\end{array}$ \\
\hline $\begin{array}{c}\text { Min. BER for } \\
\text { Downstream }\end{array}$ & $2.79 \times 10^{-13}$ & $9.17 \times 10^{-27}$ \\
\hline $\begin{array}{c}\text { Min. BER for } \\
\text { Upstream }\end{array}$ & $4.5 \times 10^{-19}$ & $6.7 \times 10^{-11}$ \\
\hline $\begin{array}{c}\text { Downstream } \\
\text { received signal } \\
\text { power }\end{array}$ & $-9.7 \mathrm{dBM}$ & $-7.4 \mathrm{dBm}$ \\
\hline $\begin{array}{c}\text { Upstream } \\
\text { received signal } \\
\text { power }\end{array}$ & $-6.443 \mathrm{dBm}$ & $-23.2 \mathrm{dBm}$ \\
\hline \multicolumn{2}{|c}{} & \\
\hline
\end{tabular}




\section{CONCLUSION}

We deliberate and instigated a bidirectional PON system based on RSOA for the uplink phase, different types of models were used. Our system is a very operative clarification for reinforced systems because it increases the mandate for multi-service operations and, therefore, broadband admittance, is a reliable and profitable communication system that can be supported at anytime, anywhere and at any time, medium that is necessary. It can improve the growing demand for high bandwidth service station.

The paramount part of our work presents an innovative bidirectional PON network that uses a $10 \mathrm{~Gb} / \mathrm{s}$ signal for the downlink signal and an OOK $1 \mathrm{~Gb} / \mathrm{s}$ signal for the upstream. RSOA has been used for the demodulation of a downlink signal of more than $20 \mathrm{~km}$ SMF. Furthermore, the RSOA is convenient as it accomplishes the occupations of a modulator (without the requirement for a local laser source) and an amplifier.

In the second part of it is a response to a request to increase capacity for data transmission. And the speed of the boats and various AWG RSOA is a transmission of data on the speed and with great courage, and the transmission of rules to achieve the PON.

From the simulation and also the results tired this analysis, once mistreatment the NRZ committal to writing technique within the BPON system, the BPON has higher performance compared to once the RZ committal to writing technique is employed. This is often as a result of two factors. At short fiber length distances and for fewer range of users, the BPON system features a higher acceptable most letter of the alphabet issue, minimum bit error rate, and eye height.

Finally, we discussed the PON bidirectional system (downstream and upstream) with AWG in RN and bidirectional reflective filter in the UN. The RFB in the downlink signal is used to reflect the return signal to the OLT. When examination today's networks with future networks, the most characteristics of future networks are the increase in information measure required to handle the network and also the optical networking which will be demanded altogether elements of the design. As a result of these two main options, these have a control on the requirements for future optical mechanisms and technology.

\section{REFERENCES}

[1] Chinky rani, Kulwinder singh, and Bhawna utreja,"Performance analysis of bidirectional broadband passive optical network using travelling wave semiconductor optical amplifier," International Journal of Engineering Research and Applications (IJERA), vol. 3, no. 4, pp. 114-118, Jul-Aug 2013.

[2] Deeksha Kocher, "Investigation of FTTH Architectures Based on Passive Optical Networks," THAPAR UNIVERSITY, Punjab, Thesis 2012.

[3] H.K.V. Lorsch, Fibre Optic Communication Key Devices, Herbert Venghaus and Norbert Grote, Eds. Atlanta, USA: Springer-Verlag Berlin Heidelberg, 2012.

[4] Gerd Keiser, Optical Fiber Communication, Fifth Edition Ed. New Delhi, McGraw Hill Education (India) Private Limited, 2013.

[5] Alaa Hamza Khader, "Bidirectional Wave Division Multiplexing Passive Optical Networks," The Islamic University of Gaza, Gaza, 2013.
[6] A. K. Jaiswal, Anil Kumar, Santosh Tripathi, and Amarendra Kumar Chaudhary, "To Study the Effect of BER and Q-factor in Intersatellite Optical Wireless Communication System," IOSR Journal of Electronics and Communication Engineering, vol. 3, no. 4, p. 19, Sep-Oct. 2012.

[7] M.F.L Abdullah and Rahmat Talib, "Multilevel Signal Analyzer Tool for Optical Communication System," International Journal of Electrical and Computer Engineering (IJECE), vol. 2, no. 4, pp. 529-536, August 2012.

[8] Raj Bala, Mrs. DivyaDhawan , and Dr. Neena Gupta, "A Novel Approach for System Modeling to Transmit Voice, Video and Data Using OFDM in FTTH Networks," IEEE, 2011.

[9] Arashdeep Kaur and Ramandeep Kaur, "Design and Performance Evaluation of 20GB/s Bidirectional DWDM Passive Optical Network Based on Array Waveguide Gratings," International Journal of Advanced Research in Electronics and Communication Engineering (IJARECE), vol. 2, no. 9, September 2013.

[10] Radim SIFTA, Petr MUNSTER, Ondrej KRAJSA, and Miloslav FILKA,"Simulation of bidirectional traffic in WDM-PON networks," PRZEGLĄD ELEKTROTECHNICZNY, 2014.

[11] A. K. Jaiswal, Anil Kumar, Santosh Tripathi, and Amarendra Kumar Chaudhary, "To Study the Effect of BER and Q-factor in Intersatellite Optical Wireless Communication System," IOSR Journal of Electronics and Communication Engineering (IOSR-JECE), vol. 3, no. 4, Sep-Oct. 2012

[12] A. Ehrhardt, F. Escher, L. Schürer, H.-M. Foisel, A. Templin, M. Adamy, and C. Gerlach, "PON Measurements and Monitoring Solutions for FTTH Networks during Deployment and Operation," IEEE, 2011.

[13] S. F. Shaukat, U. Ibrahim, and Saba Nazir, "Monte Carlo Analysis of Broadband Passive Optical Networks," IDOSI Publications, vol. 12, no. 8, 2011.

[14] Yasser Almalaq and Mohammad Matin, "Performance Analysis of Bi-Directional Broadband Passive Optical Network Using Erbium-Doped Fiber Amplifier," in SPIE, San Diego, 2014, pp. 9216-59.

[15] Redhwan Q. Shaddad, Abu Bakar Mohammad, Sevia M. Iris, Abdulaziz M. Alhetar, and Nasir A. Al-geelani , "Emerging Optical Broadband Access Networks from TDM PON to OFDM PON," in PIERSProceedings, Kuala Lumpur , 2012, pp.102-206.

[16] Khadijah Ismail, P. Susthitha Menon, Hesham A. Bakarman, Ahmad Ashrif A Bakar, and NorhanaArsad, "Performance of 18 Channel CWDM System with Inline Semiconductor Optical Amplifier," in $3^{\text {rd }}$ International Conference on Photonics 2012, pp. 215-219.

[17] P.P. Hema and Prof. A. Sangeetha, "Analysis of four channel CWDM Transceiver Modules based on Extinction Ratio and with the use of EDFA," International Journal of Engineering and Technology (IJET), vol. 5, no. 3, pp. 2895-2902, Jun-Jul 2013.

[18] F. I. El-Nahal and A. Hakeim M. Husein, "Bidirectional WDM-PON architecture using a reflective filter and 
cyclic AWG” Optik - Int. J. Light Electron Opt., Volume 122, Pages 1776-1778. Issue 19, October 2011.

[19] A. Banerjee, Y. Park, F. Clarke, H. Song, S. Yang, G. Kramer, K. Kim, and B. Mukherjee, "Wavelengthdivision-multiplexed passive optical network (WDMPON) technologies for broadband access: a review," J. Opt. Network., vol. 4, no. 11, pp. 737-758, Nov. 2014.

[20] F. J. Effenberger, "The XG-PON system: Cost effective $10 \mathrm{~Gb} / \mathrm{s}$ access," IEEE J. Lightwave. Technol., vol. 29, no. 4, pp. 403-409, Feb. 2011.

[21] K. Prince, T. B. Gibbon, R. Rodes, E. Hviid, C. I. Mikkelsen, C. Neumeyr, M. Ortsiefer, E. Rönneberg, J. Rosskopf, P. Öhlén, E. In de Betou, B. Stoltz, E. Goobar, J. Olsson, R. Fletcher, C. Abbott, M. Rask, N. Plappert, G. Vollrath, and I. T. Monroy, "GigaWaM-NextGeneration WDM-PON enabling gigabit per-user data bandwidth,” IEEE J. Lightwave Technol., vol. 30, no. 10, pp. 1444-1454, May. 2012.

[22] Infinities Research (Staff of Broadband Access research division), PON, FTTH, and DSL Aggregation Equipment and Subscribers Campbell, CA, Nov. 2011 [Online]. Available: http://www.infonetics.com/research.asp?cvg=Broadband

[23] H. S. Shin, D. K. Jung, D. J. Shin, S. B. Park, J. S. Lee, I. K. Yun, S. W. Kim, Y. J. Oh, and C. S. Shim, " $16 \times 1.25$ Gbit/s WDM-PON based on ASE-injected R-SOAs in 60
${ }^{\circ} \mathrm{C}$ temperature range," in Proc. OFC/NFOEC, paper OTuC5, 2011.

[24] S.-B. Park, D. K. Jung, D. J. Shin, H. S. Shin, I. K. Yun, J. S. Lee, Y. K. Oh, and Y. J. Oh, "Colorless operation of WDM-PON employing uncooled spectrum-sliced reflective semiconductor optical amplifiers," IEEE Photon. Technol. Lett., vol. 19, no. 4, pp. 248-250, Feb. 2010.

[25] K. Y. Cho, Y. Takushima, K. R. Oh, and Y. C. Chung, "Operating wavelength range of 1.25-Gb/s WDM PON implemented by using RSOA's," in Proc. OFC/NFOEC, paper OTuH3, 2008.

[26] D. C. Kim, B.-S. Choi, H.-S. Kim, K. S. Kim, O-K. Kwon, and D.-K. Oh, "2.5 Gbps operation of RSOA for low cost WDM-PON sources," in Proc. ECOC, Sep. 20 24, paper P2.14, 2009

[27] A. Borghesani, I. F. Lealman, A. Poustie, D. W. Smith, and R. Wyatt, "High temperature, colourless operation of a reflective semiconductor optical amplifier for 2.5 Gbit/s upstream transmission in a WDM-PON," in Proc. ECOC, 2010

[28] P. Chanclou, F. Payoux, T. Soret, N. Genay, R. Brenot, F. Blache, M. Goix, J. Landreau, O. Legouezigou, and F. Mallécot, "Demonstration of RSOA-based remote modulation at 2.5 and 5 Gbit/s for WDM PON," in Proc. OFC/NFOEC, paper OWD1,2011. 